\title{
Erratum to: Macroparasites of introduced parakeets in Italy: a possible role for parasite-mediated competition
}

\author{
Emiliano Mori $^{1,7}$ • Leonardo Ancillotto ${ }^{2,3}$. Jim Groombridge ${ }^{4}$ - Theresa Howard ${ }^{5}$. \\ Vincent S. Smith ${ }^{5} \cdot$ Florin Feneru $^{5} \cdot$ Mattia Menchetti $^{6}$
}

Published online: 17 June 2015

(C) Springer-Verlag Berlin Heidelberg 2015

\section{Erratum to: Parasitol Res}

DOI 10.1007/s00436-015-4548-2

Dr. Florin Feneru should be listed as the sixth author. His affiliation is Department of Life Sciences, Entomological Collections, Molecular Collections and Plants, The Natural History Museum, London, UK. His contributions are as follows: remarkable help in parasites identification. He has no competing interests to declare.

The online version of the original article can be found at http://dx.doi.org/ 10.1007/s00436-015-4548-2.

Emiliano Mori

moriemiliano@tiscali.it

1 Department of Agricultural, Forest and Food Sciences, University of Turin, Grugliasco, Turin, Italy

2 Department of Biology and Biotechnologies "Charles Darwin”, University of Rome "La Sapienza", Rome, Italy

3 Wildlife Research Unit, Dipartimento di Agraria, Laboratorio di Ecologia Applicata, University of Naples "Federico II", Naples, Italy

4 Durrell Institute of Conservation and Ecology, School of Anthropology and Conservation, University of Kent, Canterbury, UK

5 Department of Life Sciences, The Natural History Museum, London, UK

6 Department of Biology, University of Florence, Florence, Italy

7 Di.S.A.F.A., Entomology and Zoology, University of Turin, Largo Paolo Braccini, 2, Grugliasco, 10095 Turin, Italy 